\title{
Food tourism initiatives: resistance on the ground
}

\author{
S. L. Slocum \& S. Everett \\ Division of Tourism, Faculty of Education and Sport, \\ University of Bedfordshire, UK
}

\begin{abstract}
Food tourism has gained academic and, more recently, political recognition as a potentially sustainable form of tourism development. While state intervention in agriculture policy and the economic context for agricultural production has been long established, a new policy framework that integrates support for farming together with rural development and the environment as a means to create new jobs, protect and improve natural resources, and support rural communities has become evident in food tourism initiatives across the United Kingdom. These interventions are partly a response to the Policy Commission on the Future of Farming and Food (PCFFF) and have resulted in increased emphasis and programme development in food tourism as a means to support rural agricultural areas. It is argued that the economic motivations behind these policy developments are derived from two sources: utility goals that concern the contribution of the farming sector towards the overall health of the economy; and equity goals that focus on the provision of satisfactory incomes for rural populations.

In preparation for a new national food tourism website, a series of stakeholder interviews were conducted to gauge industry challenges in implementing food tourism across the UK. Within an established top-down approach to agricultural development, local and regional food organisations have developed food tourism initiatives with the mindset that producers need information and persuasion in order to engage with emerging tourism supply chains. Common challenges to this tactic include the geographical dispersion of producers; confusing and conflicting information available on best practices; and identifying the varying needs between small and large farm operations. However, additional struggles have been identified relating to the differing social identities of the meaning
\end{abstract}


behind 'farmer'. Many agricultural producers view their craft as a lifestyle operation rather than a business and oppose pressure to increase their management obligations through increased supply chain complexity and the need to incorporate additional personnel.

Keywords: food tourism, community development, farming policy, tourism supply chain.

\section{Introduction}

Following the Foot and Mouth epidemic in 2001, farm diversification became a major policy focus across the UK as a means to revitalise the troubled agricultural industry [2]. National policy support has emerged that unite local food and farming with regional distinctiveness [4] and has provided an avenue to enhance the provision of tourism product offerings across the country. The result is that food is increasingly becoming part of the sustainability agenda for many communities around the UK and emphasis has been placed on food tourism to supplement the agricultural sector [5]. Everett and Aitchison [1] claim that food tourism is important in strengthening a region's identify, sustaining cultural heritage, easing fears of global food homogenisation, and supporting a region's economic and socio-cultural foundation. Therefore, foodthemed pursuits can increase community identity while providing an avenue for economic development [6]. By reconnecting consumers with the land and the food-producing environments [1], the formation of food tourism schemes are two-fold: to fulfil utility goals that involve the contribution of the farming sector in the overall health of the economy; and enhance equity goals that focus on the provision of satisfactory incomes for rural populations [7].

Regions across the UK have recently given food tourism much attention in their regional development initiatives and tourism action plans. Scotland currently markets itself as the "Land of Food and Drink" and has become a leader in promoting the triple-bottom-line of economic, social and environmental sustainability through increased tourism-agriculture linkages. Wales is also pushing a food tourism strategy and states its agenda as, "co-operating across traditional boundaries and compartmentalised thinking to bring together the two industries of agriculture and tourism" [8: p. 5]. Regions across England have begun to make headway in uniting local food production and tourism although adoption has been sporadic and highly provincial due to the regional planning framework employed in the country [9]. Organisations, such as Food for Britain, have engaged in the development of Britain's specialty food sector by incorporating food tourism marketing tools in partnership with local agencies but have neglected to bring together the food and tourism sectors to stimulate tourism-induced economic activity [9].

The policy framework in the UK has created a number of barriers to the success of food tourism initiatives. The UK has traditionally employed a topdown approach to agricultural development [3]; therefore local and regional food organisations have developed food tourism initiatives within the existing policy structure. Agricultural development often starts with the notion farmers must be 
convinced to adopt new technologies [3]. With diversification, pressure now exists to "persuade" farmers that tourism markets are viable and profitable. Policies concerning tourism in rural areas are often focused on the stimulation of visitor numbers, with emphasis on marketing the potential for rural tourism and assuring a means of access for visitors [10]. Therefore, producers are often excluded from the decision making processes and are expected to accommodate the behaviours and patterns of the visitors. Moreover, policy incorporating a food emphasis in regional tourism promotion has shifted the approach of tourism development from a sectorally-based to a territorial-based strategy, resulting in fragmented application and implementation from town to town and region to region [9].

While the emerging research greatly supports food tourism as a viable and sustainable form of tourism product [11], an analysis of implementation procedures has yet to be addressed in the academic literature. The key issue rests on how policy makers choose an appropriate mix of solutions, how these are integrated, and how farmers, consumers and other stakeholders are involved in the process of reform itself [3].

\section{Literature review}

\subsection{Food tourism}

The literature on food tourism has significantly increased over the past ten years, with dedicated texts [11, 12, 13], and articles [1, 14] raising awareness of this multifaceted subject area. A lot of previous research has tended to focus on food as an economic commodity and its economic linkages [8], destination marketing strategies $[15,16]$ and quantitative consumer analysis [17, 18] which has meant that work of a sociological or cultural orientation has been stifled. However, recent work has recognised food as a communicator of cultural meaning as well as a material object able to help interrogate contemporary socio-cultural relationships $[19,22]$. In seeking to identify synergies across the various academic disciplines that have examined the sociology of food to develop tourism studies and simultaneously inform current policy and government initiatives, academics are increasingly sympathetic with Scarpato's [21, p. 60] plea that multiple disciplinary approaches must be embraced to 'allow tourism and gastronomy scholars to claim centrality for their work' and adequately reflect the importance of this multi-sensual form of tourism engagement [22].

The growth of this new form of post-Fordist tourism experience has certainly been fuelled by reconfigured consumption patterns and a desire for less packaged, niche, more individual and less formalised modes of tourism consumption [23]. A desire for 'tasting the world' [24, p. 244] and placing the 'world on a plate' [25] has become a popular pursuit. Consequently, there is an emphasis placed on understanding the tourist consumer, but often at the expense of the producer. The focus is often on touristic experience, motivations and their impact on the destination [14] or on developing frameworks to inform policy decision-making or regional marketing strategies $[18,26]$. Similarly, Hall et al. 
[11] are overtly consumption-focused in their choice of case studies and despite Boniface [12] claiming it is a 'ripe time for producers', the narrative is focused on responding to consumer demand and reacting to tastes of the 'new tourist' [23].

Although there are studies that elicit data from food producers, such as Kneafsey and Ilbery's [27] West Country survey, it is difficult to locate a study that simultaneously examines the relationships between producers and consumers in this new culinary experience. Few studies have addressed the impact of food related tourism on those producers in the regions, including Long [13] whose contributors generally concentrate on the tourist and their experience, with little discussion of its impact on the destination's culture and community. This tendency is also evident in Boniface [12], which focuses on the tourist, rather than the host culture. It is openly admitted by Hjalager that "there are clearly many gaps in our knowledge" [28, p. 233], which include the need to approach the study of food from different perspectives through the pursuit of creative and innovative lines of enquiry which will, in turn, uncover new avenues of food research.

Studies on the United Kingdom as a food tourism destination remain relatively scarce, even in the light of numerous high profile marketing campaigns such as Food from Britain (2004). In 2003, Boniface [12] was one of the few authors to pay particular attention to the British Isles, referring to a 'turning point' in how the UK uses its countryside; its response to farming crises; its growing concern regarding the quality of food; and its increasing market for organic and local produce. It provided a useful analysis on the evolution of the food and drink industry and an acute awareness of the latest government policy developments. Although no specific location is mentioned, her discussion supports increasing work on how producers are responding to policy directives through regional taste trails [29]; and regional initiatives such as the "Taste of Wales" [30].

Globalisation is a concept closely associated with the destruction of local cultural identities and the encroachment of homogenising westernised consumer culture. This is most clearly apparent in the relationship between traditional rural lifestyles and the growth in initiatives that harness the growing interest in regional and unique food. There is much to suggest a link between the growth of food tourism and the regeneration of rural areas and communities. Butler et al. [31] and Hall and Roberts [32] reflect a growing recognition by academics and policy makers that rural businesses must embrace integrated development and diversification into the tourism sector in order to survive. These publications evaluate how food-related tourism is being pushed to assist in helping sustain rural communities and livelihoods. From festivals promoting local produce [33] to farm stays and wine tourism [34], the connections to food and drink tourism are made obvious. However, much of the research is profit seeking and market focused, looking to encourage economic partnership and increase consumer demand. There needs to be more research that considers the concerns and issues that exist beyond purely economic regeneration. Bessière [35] was one of the few writers to recognise the powerful alliance between rural tourism, gastronomy 
and identity, where "rural tourism can be a part of the re-appropriation of our gastronomic history" [35, p. 116]. Bessière suggests that rural areas and food tourism have a fundamental role to play in stemming the tide of perceived globalisation and social homogenisation, "ultimately, it is the erosion and standardisation of traditional culinary practices that allows us to understand the resurgence of rural gastronomy...rural areas are thus seeing themselves becoming spaces of reconciliation, welcome and affirmation of culinary heritages" $[35, \mathrm{p}$. $118]$.

Richards [36] also insists that the tensions between globalisation and localisation are producing greater variation in our post modern societies. However, Urry is keen to outline the complex nature of interconnections and the dimensions of "global cultural flows" [37, p. 152] and advocates the closer analysis of individual localities and regions. This paper recognises that food tourism may be presented as the panacea to homogenisation and standardisation, but as new rural policy frameworks seek to engage agricultural producers, the pressure to embrace these new food tourism initiatives is perhaps also regarded as a threat to their own individual lifestyles. This research suggests there is a paradox. It seems food tourism has developed in reaction to standardisation of food, yet the pressure to come together and support wider initiatives is apparently triggering very similar concerns relating to conformity and obligations to grow and develop beyond their physical food product into something that meets a 'food tourism' policy agenda.

\subsection{Food tourism and agricultural policy development}

Over the past few years there has been significant progress in the level of convergence between policy development and academic research. Following high profile farming and food crises, there has been an explosion of interest in these industries as evidenced within national, regional and local policy documentation and implementation. Hjalager and Corigliana [38, p. 281] state "the development and standards of food for tourists are not determined uniformly by tourism policies, but more significantly by national economic, agricultural and food policies," which summarises the current situation within the British Isles. As outlined, the most significant move by the government following the Foot and Mouth crisis was the creation of the Policy Commission on the Future of Farming and Food (PCFFF) in August 2001 which was charged with the task of discovering "how we can create a sustainable, competitive and diverse farming and food sector which contributes to a thriving and sustainable rural economy" [2, p. 5]. Although not specifically directed at developing food tourism, the published report clearly recognised it as a significant means of achieving its overall objective of sustainable farming through reconnection with its consumers and the environment. Whilst not being overly radical in its suggestions, it directly influenced subsequent national government strategies (Department for the Environment, Food and Rural Affairs (DEFRA)), and regional delivery plans [4]. Although such documents stress the economic needs and market future of the industry, there is an increasing concern that social, 
cultural and environmental sustainability within the country and its regions must be achieved.

The PCFFF report states that "it is our strong view that the farming and food industry is on a path that cannot be sustained in the long term" [2, p. 13]. One of its key recommended strategies to improve this situation is diversification and the report specifically highlights tourism as the most common form of farm diversification. As previously discussed in the academic literature review, rural and farm tourism is increasingly regarded as a significant means of boosting a struggling agricultural industry and sustaining a rich and diverse rural heritage and landscape. This sentiment is re-emphasised within the government's official response to the Commission's findings [39]. Although clearly concerned with other areas of the farming industry such as Common Agricultural Policy reform, European Union involvement and the overall health of the nation, the DEFRA publication acknowledges the need to diversify outside the traditional boundaries of farming and use the wider resources of individual farms [39].

Perhaps most significantly, January 2010 saw the launch of the Government's much-publicised and ground-breaking new food strategy 'Food 2030' [51] which sets out a vision of what they want the food system to look like in 2030, and how it might be achieved. Claiming to be the first of its kind in over 50 years, it lays out ambitious targets and objectives where consumers' demand is "met by profitable, competitive, highly skilled and resilient farming, fishing and food businesses, supported by first class research and development", where "Achieving a sustainable and secure food system for 2030 depends on everyone in the food system working together" [40, p. 5].

It is apparent from the policy literature that local and regional food collaboration is regarded as one of the key ways to secure the future of the British farming industry. The concept of reconnecting farmers with their regional market and the wider players within the food chain features centrally within the main body of the PCFFF report [2] and the Food 2030 strategy. The strategies recommend improving market access within regions by establishing cooperatives and encouraging the wider use of collaboration between each producer, [2, $\mathrm{p}$. 37]. Eastham's [41] policy-based essay claims that five years ago the idea of promoting recoupling within the supply chain was absent from most policy documents and it is only recently that public bodies are driving home the ideas which have been present within earlier academic research. For example, The South West South West Strategy of Sustainable Farming and Food Steering Group [42] dedicates large sections of its report to discussing the implementation of knowledge exchange systems, unified business support services and collaborative development initiatives, all of which fall in line with this relatively new emphasis on "reconnection". In essence, policy documentation is now being designed "to create economically and socially sustainable rural communities" [41, p. 240] while strengthening the industries which give rural regions their identity.

This concept of reconnecting the consumer to the farmer and the landscape has influenced other recent government strategies and policies. The white paper Our Countryside: The Future - A Fair Deal for Rural England [4] concerns itself 
with the aim of sustaining and enhancing "the distinctive environment economy and social fabric of the English countryside" [4, p. 6]. Although it addresses a variety of rural issues which do not fall under the current focus of food tourism, it expresses a deep passion to conserve the landscape, protect traditions and sustain vital industries and ways of life. It expresses an awareness of the importance of promoting speciality and regional foods to visitors as well as the need for farms to diversify their business by running tourist-focused enterprises such as farm shops and farm stays. The concept of assurance schemes such as the Red Tractor scheme [2, p. 39] and speciality food groups such as 'A Taste of the West' [4, p. 94] are indicative of this belief that producers must offer value added products in order to encourage consumers to buy local food over cheaper global produce. It is perhaps the Countryside Agency's Eat the View programme [43] which went the furthest in promoting the importance of increasing consumer awareness of the links between the products they buy and the local countryside. The project acknowledges that there has been a loss of countryside character and distinctiveness and seeks to rectify this loss of identity through reconnection with local produce. It claims that interest in local food is growing and consumer interest is raised which helps protect regional distinctiveness. Further research should determine whether this is an achievable vision and assess how successful these government suggestions are in achieving economic growth, and ensuring food based traditions are sustained.

\section{The project}

In 2009, a group of food industry professionals, regional food and tourism organisations, agricultural producers, and tour operators collaborated to form a web-based marketing tool for food tourism across the UK. Preliminary studies were conducted to assess the diverse needs of all sectors involved as a means to develop a sustainable and diversified food tourism website. The website was to serve two main functions. The first objective was to develop a one-stop marketing tool for tourists interested in sourcing local food while on holiday, learning about and experiencing traditional food production techniques, and exploring local traditions through local recipes and regional cuisine. The second objective was to provide a portal for information exchange and the dissemination of best practices to tourism agencies new to working with food producer and vice versa, to food agencies exploring emerging tourism markets.

\subsection{Methodology}

This research involved a two-step process of data collection. First, a series of tourist surveys were conducted at three of the UK's leading food festivals during the summer and autumn of 2009: the Abergavenny Food Festival (Wales), the Stratford Festival (England), and the East Midlands Food Festival (England). The purpose was to examine how food-related tourism can deliver social, cultural and environmental sustainable development in rural regions and communities, and then develop tangible and practical solutions to achieve this. 
Next, stakeholder interviews were conducted via telephone to a variety of organisations exploring or participating in food tourism initiatives. Participants included tourism consultants, food festival organisers, local government organisations, food-based non-profit groups, agricultural producers and tour operators. In total 16 interviews were conducted during the spring of 2010 . The four key objectives of the interviews were: to engage and secure the support of regional bodies responsible for the delivery of food tourism; to recruit significant numbers of active food tourism providers and identify long-term partners to assist in the delivery and sustainability of this project; to identify barriers to food tourism provision, development and consumer engagement; and to solicit advice of the long-term management and sustainability of the food tourism website. However, for the purposes of this paper, the data derived from the stakeholder interviews are used to address the third objective in relation to barriers (perceived and real) to development which are identified and discussed.

\section{Finding and discussion}

In order to understand the potential of food tourism as a rural revitalisation tool and agricultural diversity strategy, it is vital to understand the convergences and tensions facing food and tourism organisations in the attempt to bring together two diverse industries. The participants in this study face a number of common insights in negotiating the complex relationship between tourism and agriculture. Both sectors consider local food production a valuable expression of cultural and regional identity that preserves local heritage and reflects a unique lifestyle and value set. It was widely agreed that food tourism can cumulatively expand economic opportunities for food producers and food service providers, encouraging economic growth through job creation and increases in earnings. However challenges faced by the participants include a lack of understanding and available knowledge on food tourism, in particular: information regarding the role food plays in destination branding; access to food tourists and an understanding of their motivations; and innovative partnerships that incorporate food into the tourism offering. Building a regional destination brand based on local food production requires best practice knowledge that encourages a wider use and better promotion of locally sourced food. Often restaurants have no knowledge of the source of their food, and if produced locally, fail to capitalise on the marketing potential of localisation. Participants feel that producer and food service complacency limits the establishment of networks and the sharing of information which could potentially enhance the tourism distribution system and establish a viable local supply chain. Farmers have established a traditional means of distribution and often are unaware of what happens to their produce once it leaves the farm. Food service providers rely on industry distribution systems that provide low cost and well-rounded inventories, facilitating a onestop shopping experience. Networking between these two links in the value chain has proven complex because channels of communication are nonexistent. The perception is that producers want to acquire the highest price for their commodities, whereas food service providers want to negotiate the lowest cost of 
their food staples. Outside of the hospitality industry, there is limited evidence of alternate food tourism collaborations. The regionalisation of agricultural, and more specifically tourism, has limited the transference of information regarding successful food-based attractions, farm-based travel experiences, and other innovative food tourism partnership ideas. Both sectors posses limited understand of the other, and often work dichotomously, rather than congruently, when promoting programmes and agendas.

The nature of farming has lead to resistance against the newly formed food tourism policy agenda. On the one hand, local agricultural producers face numerous options and pressures, to diversify their offerings. Proposals involving equine services, animal food production, farm structure letting and the exportation of surplus produce were investigated by the study participants. Many producers feel that food tourism is the latest trend promoted by rural development agencies, which may lose steam, thus reduced funding, when the political tide changes. On the other hand, producers face many tangible constraints that pose challenges to food tourism. Producers tend to be widely dispersed geographically, decreasing access to tourism markets. Many local producers view their trade as a lifestyle business, maintaining reluctance to commercial pressures and preferring to engage in small-scale operations. Growth of the agricultural business forces farmers to adopt new administration skills, such as personnel management. Resources needed to navigate food tourism markets vary according to firm size, isolating small-scale producers with fewer resources over large scale operations. Small producers lack economies of scale and unique selling points and cannot compete in the fragmented tourism sector.

Government agencies have been tasked with remedying many of these constraints in food tourism development. In most regions around England, it appears that tourism divisions within local government have undergone the food tourism development, whereas in Wales and Scotland these programmes are derived from the food and drink sector. While there are exceptions to the rule, the bottom-up food and drink sector appears to generate stronger ties between the industries because they more often solicit local group buy-in, whereas tourism bodies, competing for the rural traveller, often struggle against neighbouring areas and face fragmented regional government entities. During the interviews, it was more common to find governmental tourism employees engaged in part time employment than their agricultural counterpart. Moreover, the food and drink sectors, which have a stronger industry influence, are strategically placed between the producers, who are the agents of supply, and tourist, who are the customer. The food and drink framework suggests that initiatives can be championed by local producers working within groups and, on the whole, indicates a pattern of better collaboration through knowledge exchange systems and unified business support services more prevalent in an industry-run sector, rather than through public organisations. 


\section{Conclusion}

This article has indicated that food tourism is still in its infancy as a rural development tool in the U.K. While regional development agencies have begun to explore the rural revitalisation potential of partnering locally sourced produce with emerging tourism markets, there are still a number of obstacles in the implementation of recent policy agendas. This study has shown that two topdown approaches are currently being applied simultaneously, either through tourism-based initiatives or through agricultural focused schemes. Both paths have sustained challenges and opposition caused by a lack of information and knowledge exchange between the two multifarious sectors. While numerous studies have examined the sociology and economic contribution of food in regional development, the implementation strategies of food tourism partnerships require further assessment into the key aspects of diversity between the two sectors.

\section{References}

[1] Everett, S. and Aitchison, C., The role of food tourism in sustaining regional identity: a case study of Cornwall, South West England. Journal of Sustainable Tourism, 16(2), pp. 150-167, 2008.

[2] Policy Commission on the Future of Farming and Food (PCFFF), Farming and Food: A Sustainable Future. Online. http://archive.cabinetoffice. gov.uk/farming/pdf/PC\%20Report2.pdf. Accessed 28 October 2006.

[3] Pretty, J.N., Agri-Culture: Reconnecting People, Land and Nature. Earthscan: London, UK, 2002.

[4] Department for Environment, Food and Rural Affairs (DEFRA), Our Countryside: The Future - A Fair Deal for Rural England. Government White Paper, 2002.

[5] Sharples, E., Food tourism in the Peak District National Park, England. In C.M. Hall, E. Sharples, R. Mitchell, N. Macionis and B. Cambourne (eds). Food Tourism Around the World: Development, Management and Markets (pp. 206-227). Oxford: Butterworth Heinemann, 2003.

[6] Rusher, K., The Bluff Oyster festival and regional economic development: Festivals as culture commodified. In C. M. Hall, E. Sharples, R. Mitchell, N. Macionis and B. Cambourne (eds). Food Tourism Around the World: Development, Management and Markets (pp. 193-205). Oxford: Butterworth Heinemann, 2003.

[7] Simms, R., Food, place and authenticity: local food and the sustainable tourism experience. Journal of Sustainable Tourism, 17(3), pp. 321-336, 2009.

[8] The Welsh Assembly. Food Tourism Action Plan: Food and Drink for Wales. http://www.walesthetruetaste.co.uk/userResources/Food\%20 Tourism\%20PDF.pdf. 2010.

[9] Boyne, S., Hall, D., and Williams, F., Policy, Support and Promotion for Food-Related Tourism Initiatives: A Marketing Approach to Regional 
Development. Journal of Travel and Tourism Marketing, 14(3), pp. 131154, 2010.

[10] Ilbery, B. and Bowler, I., From Agricultural Productivism to Post Productivism. In B. Ilbery (eds). The Geography of Rural Change, Harlow, (pp. 57-84). UK: Pearson Education Ltd., 1998.

[11] Hall, C.M., Sharples, E., Mitchell, R., Macionis, N. and Cambourne, B. (eds). Food Tourism Around the World: Development, Management and Markets. Oxford: Butterworth Heinemann, 2003.

[12] Boniface, P., Tasting tourism: travelling for food and drink. Aldershot: Ashgate, 2003.

[13] Long, L., Culinary tourism. Kentucky: The University Press of Kentucky, 2004.

[14] Hall, C. M. and Mitchell, R., We are what we eat: food, tourism and globalization. Tourism Culture and Communication, 2, pp. 29-37, 2000.

[15] Hashimoto, A. and Telfer, D.J., Selling Canadian culinary tourism: branding the global and the regional product. Tourism Geographies, 8(1), pp. 31-55, 2006.

[16] Kivela, J. and Crotts, J.C., Tourism and gastronomy: gastronomy's influence on how tourists experience a destination. Journal of Hospitality and Tourism Research, 30(3), pp. 354-377, 2006.

[17] Du Rand, G. E. and Heath, E., Towards a framework for food tourism as an element of destination marketing. Current Issues in Tourism, 9(3), pp. 206234, 2006.

[18] Ignatov, E. and Smith, S., Segmenting Canadian culinary tourists. Current Issues in Tourism, 9(3), pp. 235-255, 2006.

[19] Oakes, T., Eating the food of the ancestors: place, tradition, and tourism in a Chinese frontier river town. Ecumene, 6(2), pp. 123-145, 1999.

[20] Van Westering, J., Heritage and gastronomy: the pursuits of the 'new tourist'. International Journal of Heritage Studies, 5(2), pp. 75-81, 1999.

[21] Scarpato, R., Sustainable gastronomy as a tourist product. In A. Hjalager and G. Richards (eds). Tourism and Gastronomy (pp. 132- 151). London: Routledge, 2002.

[22] Everett, S., Beyond the visual gaze? The pursuit of an embodied experience through food tourism. Tourist Studies 8(3), pp. 337-358, 2009.

[23] Poon, A., Tourism, technology and competitive strategies. Wallingford: CABI, 1993.

[24] Franklin, A., Tourism: an introduction. London: Sage, 2003.

[25] Cook, I. and Crang, P., The world on a plate: culinary culture, displacement and geographical knowledges. Journal of Material Culture, 1(2), pp. 131153, 1996.

[26] Fields, K., Demand for the gastronomy tourism product: motivational factors. In: A.M. Hjalager and G. Richards (eds). Tourism and gastronomy. London: Routledge, pp. 36-50, 2002.

[27] Kneafsey, M. and Ilbery, B., Regional images and the promotion of speciality food and drink Products: initial explorations from the 'West Country'. Geography, 86, pp. 131-140, 2001. 
[28] Hjalager, A. and Richards, G. (eds) (2002) Tourism and Gastronomy. London: Routledge.

[29] Boyne, S., Williams, F. and Hall, D., On the trail of regional success: tourism, food production and the Isle of Arran Taste Trail. In: A. Hjalager and G. Richards (eds). Tourism and gastronomy. London: Routledge, pp. 91-114, 2002.

[30] Jones, A. and Jenkins, I., A Taste of Wales - Blas Ar Gymru: institutional malaise in promoting Welsh food tourism products. In: A. Hjalager and G. Richards (eds). Tourism and gastronomy. London: Routledge, pp. 115-131, 2002.

[31] Butler, R., Hall, C., Jenkins, J. (eds). Tourism and Recreation in Rural Areas, Chicester: Wiley, 1998.

[32] Hall, D. and Roberts, L. (ed.), Rural Tourism and Recreation: Principles to Practice. Wallingford: CABI Publishing, 2001.

[33] Janiskee, R. and Drews, P., Rural Festivals and Community Re-imaging. In Butler, R., Hall, C. and Jenkins, J. (eds). Tourism and Recreation in Rural Areas, Chicester: Wiley, (1998), pp. 157- 175, 2001.

[34] Hall, C. M. and Macionis, N., Wine Tourism in Australia and New Zealand in Butler, R., Hall, C. M. and Jenkins, J. (eds). Tourism and Recreation in Rural Areas, Chichester, Wiley, (1998), pp. 197-224, 1998.

[35] Bessière, J., The Role of Rural Gastronomy in Tourism. In D. Hall and L. Roberts (ed.) Rural Tourism and Recreation: Principles to Practice (pp. 115-118). Wallingford: CABI Publishing, 2001.

[36] Richards, G., Gastronomy: an essential ingredient in tourism production and consumption? In A. Hjalager and G. Richards (eds). Tourism and Gastronomy (pp. 3-20). London: Routledge, 2002.

[37] Urry, J., Consuming places. London: Routledge, 1999.

[38] Hjalager, A. and Corigliana, A., Food for tourists - determinants of an image. International Journal Tourism Research, 2(4), pp. 281-293, 2000.

[39] Department for Environment, Food and Rural Affairs (DEFRA), The strategy for sustainable farming and food - facing the future. London: DEFRA, 2002.

[40] South West Strategy of Sustainable Farming and Food Steering Group (South West SSFFSG), Making a Difference: The South West Delivery Plan for Sustainable Farming and Food, Online. htttp://www.gos.gov.uk/gosw/docs/246139/165816/2004_making_differenc e_delivery.

[41] Department for Environment, Food and Rural Affairs. Food 2030, Onine. http://www.defra.gov.uk/foodfarm/food/pdf/food2030strategy.pdf.

[42] Eastham, J., Valorizing through tourism in rural areas: moving towards regional partnerships. In C.M. Hall, E. Sharples, R. Mitchell, N. Macionis and B. Cambourne (eds). Food Tourism Around the World. Development, management and markets (pp. 228-248). Oxford: Butterworth Heinemann, 2003. 
[43] Department for Environment, Food and Rural Affairs (DEFRA), Our Countryside: The Future - A Fair Deal for Rural England. Government White Paper. Online. http://www.defra.gov.uk/rural/ruralwp/whitepaper.

[44] The Countryside Agency, Eat the View: promoting sustainable local products. London: Countryside Agency, 2001. 